\title{
Notas Sobre a História Oficial do Transtorno do Déficit de Atenção/hiperatividade TDAH
}

Notes on the Official History of Attention Deficit/hyperactivity Disorder ADHD

Anotaciones Sobre la Historia Oficial del Trastorno del Déficit de Atención/hiperatividad TDAH
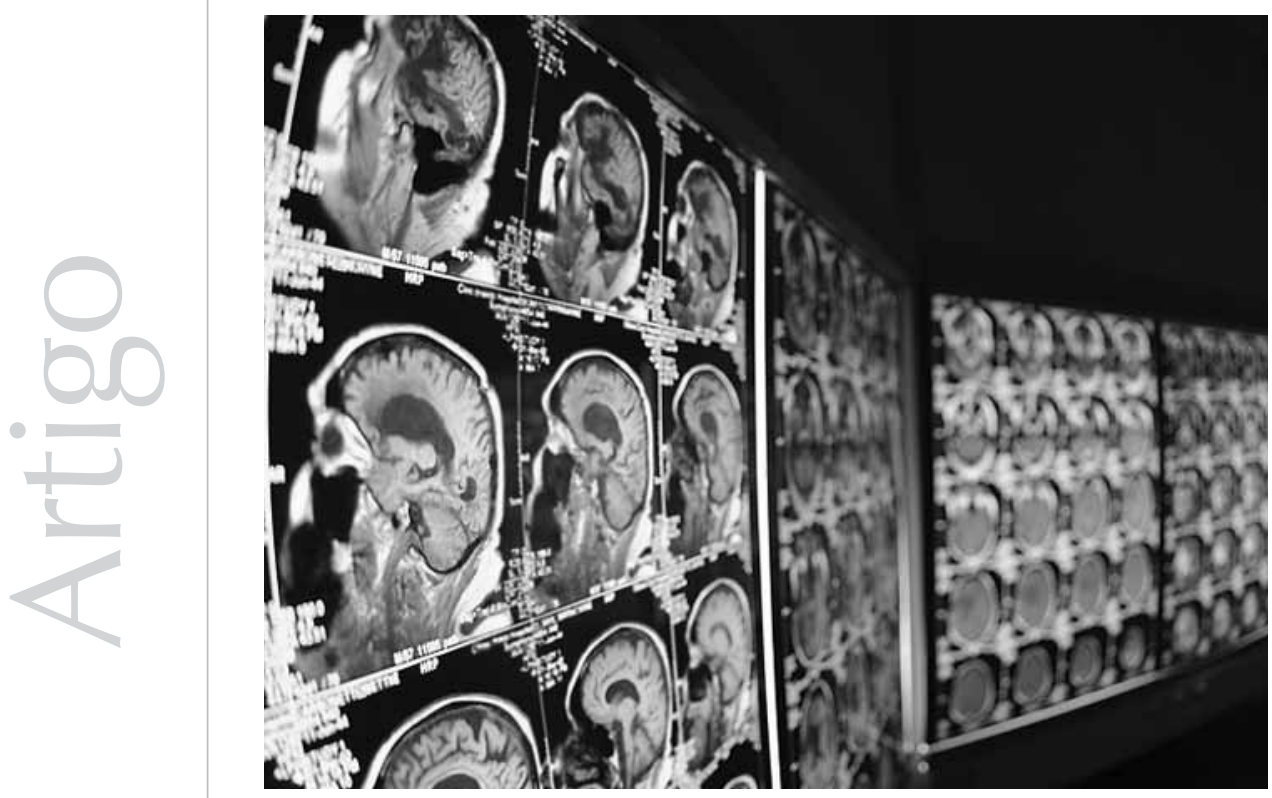
Resumo: Este artigo constrói inicialmente uma cartografia dos discursos históricos do diagnóstico do Transtorno do Déficit de Atenção/Hiperatividade (TDAH). Em seguida, dois momentos-chave da história oficial do diagnóstico são analisados: as descrições do médico inglês George Still, de 1902, e a síndrome da encefalite letárgica, na primeira metade do século XX. Em tais análises, é dado relevo aos elementos morais e políticos da história oficial do TDAH - eles fazem parte dos níveis mais profundos da constituição do diagnóstico do TDAH que não são explicitados pelo discurso médico-científico. As diferentes versões históricas destacadas e os elementos revelados e ocultados pela história oficial são vistos como parte da constituição do diagnóstico do TDAH. Juntos, eles formam a história do TDAH com todas as suas polêmicas e controvérsias.

Palavras-chave: Transtorno do Déficit de Atenção/Hiperatividade (TDAH). Constituição histórica. George Still. Encefalite letárgica.

Abstract: Firstly, this article offers a cartography of the discourses on the history of the Attention Deficit/ Hyperactivity Disorder Diagnosis (ADHD). Secondly, two main periods of ADHD official history are analyzed: the descriptions of the English physician George Still, published in 1902, and the lethargic encephalitis syndrome, in the first half of the $20^{\text {th }}$ century. The moral and political aspects of the ADHD official history are pointed out - they are seen as important parts of the constitution of the ADHD diagnosis that are not showed by medical-scientific discourses. The different historical aspects revealed and hidden by the official history of the ADHD diagnosis are described as elements of the diagnosis constitution. Together, they constitute the ADHD diagnosis history, with its polemics and controversies.

Keywords: Attention Deficit/Hyperactivity Disorder (ADHD). Historical constitution. George Still. Lethargic encephalitis syndrome.

Resumen: Este artículo construye inicialmente una cartografía de los discursos históricos del diagnóstico del Trastorno del Déficit de Atención/Hiperativida (TDAH). Enseguida, dos momentos-clave de la historia oficial del diagnóstico son analizados: las descripciones del médico inglés George Still, de 1902, y el síndrome de la encefalitis letárgica, en la primera mitad del siglo XX. En tales análisis, es dado relieve a los elementos morales y políticos de la historia oficial del TDAH - ellos hacen parte de los niveles más profundos de la constitución del diagnóstico del TDAH que no son especificados por el discurso médico-científico. Las diferentes versiones históricas destacadas y los elementos revelados y ocultados por la historia oficial son vistos como parte de la constitución del diagnóstico del TDAH. Juntos, forman la historia del TDAH con todas sus polémicas y controversias.

Palabras clave: Trastorno del Déficit de Atención/Hiperativida (TDAH). Constitución histórica. George Still. Encefalitis letárgica.

"Uma pletora de sintomas diferenciados, desde suas primeiras descrições", essa é uma das críticas de Rafalovich (2002, p. 14) ao diagnóstico do Transtorno do Déficit de Atenção/Hiperatividade (TDAH). O destaque em itálico é importante. Quais seriam as primeiras descrições do TDAH? Supostamente, essa pergunta nos levaria à investigação do transtorno nas classificações psiquiátricas. Nelas, seria preciso investigar os quadros patológicos que se aproximaram do diagnóstico recente. Após identificá-los, analisaríamos suas explicações etiológicas e suas descrições sintomatológicas. Encontraríamos um aspecto em comum forte o suficiente para agrupá-los em uma mesma história diagnóstica. No cenário mais recente, situaríamos o TDAH descrito no DSM IV-R
(2000) e a síndrome hipercinética do CID 10 (1992). Mas, quando lembramos que o diagnóstico atual é composto pela pletora de sintomas que Rafalovich comenta, a tarefa se complica. Não seria difícil encontrar vários quadros patológicos que incluíssem um defeito da atenção, da hiperatividade e da impulsividade.

Além disso, já que não é necessário que todos os sintomas estejam presentes para que o diagnóstico do TDAH seja definido, sua história poderia ser orientada pela predominância de um dos seus três sintomas centrais. Ao longo da história médica, a hiperatividade, a impulsividade e a desatenção criaram entre si laços diversos. No interior da história oficial que as vincula 
Ainda no universo infantil, Barbetti (2003) analisa a construção da criança hiperativa em sua relação com a história da eletricidade a partir da

segunda metade do século XIX, e Dupanloup (2004) também retorna ao século XIX para falar da criança hiperativa inapta e instável. e as chama de TDAH, elas alternaram entre si o lugar de maior importância na definição da classificação. Em certos momentos, o aspecto que mais caracterizava o quadro era a hiperatividade que, em seguida, foi destronado pela desatenção que, também em seguida, foi transformado em um aspecto menor das funções executivas. Houve um tempo em que nenhum deles era visto como o aspecto definidor do transtorno.

Considerando ainda que cada um dos três sintomas se desdobra em quadros mais específicos, caso estejamos falando da menina ou do menino, da criança ou do adulto com TDAH, a complicação se agrava. Poderíamos escrever a história da criança com TDAH, e, nesse caso, as descrições patológicas seriam buscadas no universo da psiquiatria, da neurologia, da Psicologia infantil e também da psicopedagogia. A relação estabelecida entre a criança com TDAH e o universo escolar é sustentada pela própria descrição do transtorno. Afirma-se que os sintomas da desatenção, da hiperatividade e da impulsividade se manifestam principalmente no ambiente da escola. Esse não é um dado insignificante, mesmo para a história oficial da desordem. Nela, os quadros precursores do TDAH estão relacionados a problemas escolares. O discurso crítico considera esse dado e analisa a história do TDAH como aquela do controle e da medicalização infantil (Schrag \& Divoky, 1975; Werner, 2001). Alguns a descrevem como um capítulo importante da história do poder institucional exercido sobre a criança indisciplinada (Conrad, 1975, 1976). Rafalovich (2002) inicia a história do TDAH com o discurso médico da criança idiota e do imbecil moral da segunda metade do século XIX. Ainda no universo infantil, Barbetti (2003) analisa a construção da criança hiperativa em sua relação com a história da eletricidade a partir da segunda metade do século XIX, e Dupanloup (2004) também retorna ao século XIX para falar da criança hiperativa inapta e instável.
Deixando de lado o universo infantil, a nossa história poderia ser também aquela do adolescente TDAH. Nesse caso, ela teria que considerar o discurso e a prática médica em torno da delinqüência e da adolescência desviante. Por outro lado, seria possível construir a história do adulto TDAH, já que, desde a década de 80 , ele também faz parte da categoria diagnóstica antes considerada prioritariamente infantil. Certamente, o percurso histórico analisado seria outro. Exagerando um pouco no argumento, nada impediria que a história do TDAH familiar fosse construída, já que agora também se diz que a desordem pode acometer toda a família. Há ainda os pesquisadores que vêem na descoberta e na utilização terapêutica das drogas estimulantes e nos interesses econômicos criados pelo seu comércio o aspecto central da constituição do diagnóstico. A maior parte deles concentra-se na história da farmacologia da Ritalina. Na literatura sobre a Ritalina, as análises mais citadas são as de Schrag e Divoky (1975), Diller (1998) e Degrandpre (2000). Essas análises foram e ainda são importantes para o debate sobre a história do TDAH.

Encontramos ainda os que, como Dumit (2000), acreditam que a validação do TDAH como um diagnóstico médico esteve e está intimamente vinculada à construção da legitimidade científica da neurologia e das tecnologias de imagem cerebral. O autor analisa o transtorno do déficit de atenção/ hiperatividade como uma das novas desordens sociomédicas ou desordens biomentais. Elas são patologias de forte repercussão legal, cujas imagens cerebrais exercem um papel importante em sua legitimação diagnóstica.

Muitos analistas sociais constroem a história do TDAH como aquela dos distúrbios produzidos pela era dos excessos da informação, do consumo material desenfreado e sem sentido, da cultura somática, das identidades descartáveis, da perda da autoridade da 
família, da igreja e do Estado. Nesse grupo, há também os que identificam um nonsense inerente à proposição da patologia da atenção e da hiperatividade. Ela encarna a forma de vida atual e, por assim dizer, normal em todas as suas destemperanças. Esses analistas questionam a existência patológica do TDAH.

Os percursos históricos do TDAH não param por aqui. No entanto, no debate público em torno do distúrbio, essa diversidade histórica raramente é comentada. A maioria das críticas direcionadas ao transtorno apoiam-se nas suas controvérsias clínicas, epidemiológicas e terapêuticas, que não são poucas. Muitas são pertinentes, necessárias e devem ganhar o debate público, mas uma atenção especial merece ser dedicada ao perfil desmemoriado do debate. Da diversidade das versões históricas oferecidas, apenas uma é reconhecida, e essa é a versão que nasce no interior do campo biomédico. Ela é contada pelos especialistas da neurologia e da psiquiatria infantil do TDAH. Eles são pesquisadores norteamericanos, canadenses e ingleses (e também brasileiros) que dedicaram, e ainda dedicam, sua vida profissional clínica e acadêmica ao estudo do transtorno. Nefsky (2004) denomina esses médicos pesquisadores historiadores internos. Eles representam o discurso da legitimidade biológica e cerebral do transtorno.

\section{Os percursos históricos do TDAH}

As formas de construir a história de um diagnóstico são muitas. Há os que a fazem isolando-o de seu espaço epistêmico e social de surgimento, outorgando a ele uma independência divina e emprestando à ciência que o gerou uma proteção olímpica. Eles desconsideram os aspectos morais, sociais, políticos, econômicos e institucionais que alimentam a constituição do fato patológico. Eles também desconsideram que os objetos científicos nascem do diálogo turbulento entre as demandas políticas e ideológicas que sustentam sua pesquisa. Mas aqueles que não outorgam a si a tarefa de garis da ciência biomédica sabem que as descrições do normal e do patológico surgem de toda essa hibridez. Em relação à história dominante do TDAH, o primeiro modo de fazer histórico predomina.

O discurso neurocientífico sobre o TDAH não é uníssono, mas também cria suas unanimidades, e nenhuma delas é mais forte do que a história do diagnóstico. Nela, a criança TDAH surgiu na literatura médica da primeira metade do século XX, e, a partir de então, foi batizada e rebatizada muitas vezes. Ela foi a criança com defeito no controle moral, a portadora de uma deficiência mental leve ou branda, foi afetada pela encefalite letárgica, chamaram-na simplesmente de hiperativa ou de hipercinética, seu cérebro foi visto como moderadamente disfuncional, ela foi a criança com déficit de atenção e, enfim, a portadora do transtorno do déficit de atenção/hiperatividade. Desde os últimos 20 anos do século XX, ela é marcada por um defeito inibitório que afeta o desenvolvimento das funções executivas cerebrais.

Chamamos essa versão histórica de oficial e dominante porque no debate científico, político, econômico e popular, ela é a história do diagnóstico do TDAH. Com raras exceções, críticos e defensores da visão neurológica partem dos marcos e das classificações psiquiátricas que ela oferece. Os primeiros, os críticos, repetem o trajeto histórico oferecido pelos segundos para denunciar a volatilidade de um transtorno que, em menos de um século de vida, mudou de classificação mais de 10 vezes, e ridicularizam a pretensa clareza e unificação do discurso neurológico. Descrições de patologias tão diversas não podem ser unificadas na mesma história ou no mesmo quadro patológico sem que uma redução indevida esteja presente. Essas 
são as raras críticas que partem da história médica do transtorno, mas que o fazem sem realmente analisar a história oferecida. Elas apenas argumentam que, historicamente, a pletora de sintomas do TDAH é incluída em uma outra pletora de diferentes descrições patológicas.

Não incluímos nossa análise em nenhum dos dois lados do debate. Embora a crítica à reunião de diferentes patologias em uma única história diagnóstica seja válida, ela desconsidera o que as patologias escolhidas teriam em comum. A história oficial do diagnóstico do TDAH é constituída por outros diagnósticos psiquiátricos problemáticos e duvidosos, situados na fronteira obscura entre as desordens nervosas definidas e indefinidas, entre as disfunções da vida normal e da patológica. Nem os historiadores internos do TDAH nem seus críticos dizem que a história do TDAH guarda-chuva seja fundamentalmente constituída por outros diagnósticos guarda-chuvas. Na maior parte das vezes, neles estavam agrupadas as patologias que colocaram em xeque o saber neurológico e psiquiátrico, mas que, por outro lado, possibilitaram seu fortalecimento. O melhor exemplo é a síndrome da encefalite letárgica, uma patologia misteriosa e obscura que desafiou o conhecimento neurológico da época da mesma forma que participou de sua legitimação (Kroker, 2004).

O próximo diagnóstico guarda-chuva incluído na história oficial do TDAH é o dano cerebral mínimo, uma classificação pouco definida, caracterizada por transtornos de comportamento, de linguagem e de aprendizado associados a uma causa orgânica imprecisa. Outras formas de descrever o quadro foram a disfunção cerebral mínima e a desordem orgânica do comportamento, e ambas também foram diagnósticos extremamente imprecisos e abrangentes. Antes da publicação do DSM III (1980), o que caracterizava o transtorno nas descrições psiquiátricas era o seu elemento motor: o excesso de movimento e a incapacidade de inibição dos impulsos. Em 1957, ele passou a ser descrito como a síndrome do impulso hipercinético, e, em 1960, foi redefinido como a síndrome da criança hiperativa. Progressivamente, a hipótese da existência de uma lesão cerebral precisa, mesmo que mínima, foi substituída pela presença de um déficit neurofisiológico. Quadros mais diversos foram incluídos no transtorno, que passava a ser causado por uma disfunção neurofisiológica branda.

A partir do final da década de 70, a ênfase diagnóstica, até então centrada na hiperatividade, concentrou-se no sintoma da desatenção. Mesmo auxiliadas pelas tecnologias visuais e cinematográficas, a análise das patologias do movimento não se adequava às exigências do novo olhar psiquiátrico em formação. A entidade foi renomeada e o diagnóstico mais uma vez ampliado: o transtorno podia ocorrer com ou sem a presença do elemento hiperativo. Nessa mesma época, a pesquisa da atenção afirmava que toda patologia mental incluía em sua sintomatologia um déficit atentivo. Na década de 90, o transtorno foi reinterpretado como um defeito inibitório no mesmo contexto no qual a falha da inibição era vista como o problema que estaria na base e no início do desenvolvimento de quase todo quadro psicopatológico.

Como o TDAH, os diagnósticos guarda-chuva agrupados em sua história fizeram parte do processo através do qual a ciência médica iniciou seu discurso sobre a saúde mental de pessoas que não eram nem drasticamente mal desenvolvidas nem mentalmente deficientes. Elas eram mal adaptadas. Os diagnósticos incluídos na história do TDAH são aqueles que fortaleceram o processo de patologização dos indivíduos incapazes de satisfazer as expectativas morais, políticas e econômicas da sociedade na qual viviam. Na história da 
psiquiatria, a patologização do indivíduo inapto ou não adaptado não é um processo recente, mas, na constituição do TDAH, ela se vincula à cerebrização das disfunções adaptativas. Nela, o sucesso e o fracasso adaptativo tornaram-se dependentes do funcionamento cerebral, de sua neuroquímica e de seus ajustamentos e correções pontuais. Em nossa análise, explicitamos os aspectos que fortaleceram os vínculos entre a biologia e a moral da atenção e alimentaram a constituição do diagnóstico do TDAH.

Partimos da história oficial do transtorno. Recorremos à análise de Russell A. Barkley, uma das autoridades mais citadas no debate internacional clínico e político sobre o TDAH. Ele é quem melhor representa a direção neurológica cognitiva da interpretação clínica e histórica do transtorno e, por assim ser, estará na base de nossas análises seguintes. Na sua teoria desenvolvida durante a década de 90, o TDAH resulta de um defeito da inibição e da capacidade de autocontrole, sendo um defeito da vontade e um déficit do desenvolvimento moral.

Ao definir o TDAH através da linguagem do autocontrole, Barkley (1997) enfatiza que seu ponto de vista não é novo. Na história do TDAH, o médico inglês George Still, no início do século, e Virgínia Douglas, no final da década de 70, defenderam um ponto de vista semelhante. Still, Douglas e Barkley teriam em comum ao menos um aspecto que, para Barkley, é o ponto central da análise teórica e histórica do TDAH: em suas análises, o que determina o transtorno da atenção e da hiperatividade é o vínculo entre um defeito neurofisiológico do sistema inibitório, o déficit da moral e da vontade. Veremos que Barkley relaciona o problema moral ao déficit inibitório. Em sua opinião, Still e Douglas haviam chegado à mesma conclusão.

Em um outro lugar (Caliman, 2006), discutimos como Virgínia Douglas foi um nome importante na constituição do déficit de atenção no contexto biomédico e moral da década de 70. Além de se adequar a pesquisa do transtorno às exigências operacionais da psiquiatria da época, ao colocar a disfunção da atenção no centro da patologia da hiperatividade, Douglas resgatava os antigos estudos das patologias da vontade e vinculavaos à pesquisa atual das patologias da atenção. Para a autora, os estudos da atenção do século XIX, principalmente as análises de William James, deveriam ser relidos e incorporados pela ciência contemporânea.

No presente artigo, não analisamos o trabalho de Douglas, apenas destacamos seu papel no processo de releitura do déficit da atenção como uma patologia da vontade. Ao resgatar a interpretação de Barkley, demonstramos que a atual categoria diagnóstica do TDAH foi constituída no interior dos dilemas morais, políticos, econômicos e tecnológicos que resgatavam, não sem importantes alterações, os antigos dilemas das patologias da vontade. Centramos nossa análise nos momentos históricos que vincularam as patologias da atenção, do movimento e da vontade: o final do século XIX e o início do século XX.

\section{George Still e a biologia da moral no início do século XX}

Na análise de Barkley (1997, p. 6) Still foi quem primeiro vinculou o transtorno da atenção a um defeito da vontade inibitória. Foi ele quem ofereceu as bases clínicas do diagnóstico do TDAH. No entanto, como veremos, a análise de George Still foi apenas uma das tantas que tinham algo a dizer sobre o assunto. Assim, analisamos o trabalho de Still com três objetivos: inserir sua análise no processo histórico de naturalização da moral, iniciado no princípio do século XIX, destacar o caráter excessivo e tendencioso da leitura neurobiológica de Barkley sobre Still e demonstrar que a interpretação atual do TDAH se vincula às tentativas de 
patologização e biologização da vontade que a antecedem e a incluem.

A história oficial do TDAH conta que, na literatura médica, ele foi primeiro um defeito do controle moral. O cenário de sua aparição foi a capital inglesa na virada do século XIX, mais especificamente, o King's College Hospital, no ano 1902. George Still é o marco obrigatório. Considerado por seus comentadores o primeiro pediatra inglês, Still foi também o primeiro professor de doenças infantis do King's College Hospital e autor de vários livros sobre o comportamento infantil normal e patológico. Ele ficou famoso pela descrição da artrite reumatóide crônica em crianças, patologia que ficou conhecida como a doença de Still. Na história do diagnóstico do TDAH, de sua vasta produção, são retomadas três conferências proferidas diante do Royal College of Physicians, no ano 1902, entituladas Algumas condições psíquicas anormais em crianças, publicadas no The Lancet, no mesmo ano (Still, 1902).

A história de Barkley (1997) sobre o transtorno é a mais citada pelos que, como ele, encontram nas Conferências de George Still a primeira descrição médica do TDAH. Para o autor, vários aspectos da análise de Still confirmam a existência biológica do transtorno e de sua manifestação clínica na virada do século. O primeiro ponto de acordo é etiológico: a condição mórbida descrita por Still e o atual TDAH resultam do defeito da função inibitória da vontade. A sintomatologia e a epidemiologia descritas são também as mesmas. Nas crianças afetadas, a punição é ineficaz. O comportamento agressivo e desafiante que está na base da criminalidade é uma manifestação comum. Entre os familiares, há relatos de alcoolismo, depressão e comportamento criminoso. Nos dois diagnósticos, a desatenção e a hiperatividade estão presentes. Observa-se o comportamento patológico orientado por gratificações imediatas, acompanhado da incapacidade de planejar o futuro. O intelecto não é afetado. As duas pesquisas legitimaram a patologia moral como uma condição mórbida independente e real porque biológica e cerebral. O objetivo era e é encontrar a sede fisiológica da vontade, da moral e do autocontrole.

As possíveis similaridades entre o TDAH e a condição analisada por Still são repetidas em todo livro e tese sobre o assunto. Elas atestam que o transtorno não é uma invenção de nossos tempos. Mas, na maior parte das vezes, esses estudos emprestam a Still uma meticulosidade neurológica e um vocabulário sintomatológico irreconhecível em suas conferências. O médico inglês era extremamente cauteloso em seus argumentos. Para ele, o debate estava em aberto. Em relação aos sintomas analisados, seus textos estão repletos de expressões condicionais do tipo se eles realmente forem (mórbidos ou não), se eles existem (como uma patologia) e de outras indeterminações do mesmo gênero. Por outro lado, os historiadores internos do TDAH nunca mencionam as questões morais, políticas e legais que norteavam os estudos de Still. Tratava-se, em primeiro lugar, de legitimar os valores morais da época ao inscrevê-los no corpo. Still foi um dentre muitos outros que postulou a existência de uma patologia moral específica, marcada pela desobediência às regras e consensos sociais. Seu nome pode ser incluído na história da naturalização da moral e moralização do natural (Caliman, 2006).

Still (1902) analisava os defeitos anormais do controle moral em crianças resultantes de uma falha no desenvolvimento mental. O médico acreditava que o controle moral normal sempre estava em conformidade com a ideia de bom ou de bem de todos (Still, 1902, Lecture I, p. 1008). Era tal controle que inibia as forças espontâneas e instintivas opostas à ideia de bem de todos. Mas, nas crianças analisadas em seu estudo, havia um defeito moral. A constituição do 
controle moral dependia da ação conjunta da cognição, da consciência moral e da vontade. Quando uma delas não funcionava, seu desenvolvimento era prejudicado. Para Still, somente a disfunção resultante do defeito da vontade inibitória era uma patologia moral específica. O defeito moral era constitutivo quando manifestado em imbecis e idiotas, mas, em sua forma mais pura, ele resultava das disfunções de um cérebro moralmente desordenado.

O controle moral variava de criança para criança. Nem sempre era possível demarcar uma linha precisa entre seu funcionamento normal e anormal, pois essa demarcação, dizia Still, era extremamente arbitrária. Em algumas crianças, sua deficiência era tão extrema e inaceitável para os padrões sociais da época que ela deveria ser mórbida. No entanto, nenhuma prova empírica oriunda da pesquisa neurofisiológica sustentava sua hipótese. As evidências que mostravam a existência do distúrbio moral derivavam da decisão social sobre o que era tolerado ou não, sobre o que se encaixava ou não em sua racionalidade.

Na decisão sobre a presença ou ausência da patologia moral, eram analisados: 1 - o grau excepcional e excessivo do defeito moral; 2 - a ausência de correspondência entre o ambiente da criança e seu comportamento (por exemplo, uma criança rica que tinha o costume de roubar coisas); 3 - a presença de comportamentos nocivos sem motivos justificáveis (a criança roubava, mas não fazia uso do objeto roubado ou devolvia-o para o dono logo depois do furto); 4 - a falha ou insuficiência da punição como ato corretivo e 5 - a consideração da história familiar e do ambiente de criação da criança. Quase todas as crianças tinham em suas famílias parentes epiléticos, alcoólatras, imorais, insanos, suicidas, mentalmente fracos ou sexualmente problemáticos. Certas anomalias físicas, ou signos de estigma, como a cabeça maior do que a média, eram também perceptíveis.

As observações de Still resultavam da análise clínica de 20 crianças nas quais eram identificados graus mórbidos de: (1) fúria emotiva, (2) crueldade e malícia, (3) inveja, (4) ausência de lei, (5) desonestidade, (6) promiscuidade e destrutividade, (7) ausência de modéstia e vergonha, (8) imoralidade sexual e (9) vício. Todas as crianças manifestavam uma necessidade mórbida de autogratificação que não considerava o bem dos outros e o seu próprio bem. Dos sintomas descritos, os mais frequentes eram a fúria emotiva e a malícia, quando dores ou desconfortos em outras pessoas eram causados, ou a crueldade, quando as vítimas dos maus tratos eram animais indefesos. Além dessas características, a resistência à disciplina e à autoridade na escola, no lar e em outros ambientes eram comuns.

Apesar da postulação da realidade biológica da patologia da vontade e da moral, em Still, as explicações sobre as causas da doença eram extremamente vagas. A hipótese da lesão cerebral deveria ser descartada, caso ela fosse compreendida como uma condição necessária à manifestação do defeito. Em sua ausência, toda interferência no funcionamento cerebral suficientemente intensa a ponto de alterar sua nutrição celular poderia causar o distúrbio moral. Devido à obscuridade da Psicologia da vontade da época, nada mais poderia ser dito, mas nenhum desses aspectos são comentados na história oficial do TDAH. Suas análises dizem que Still descobriu o defeito neurofisiológico da vontade e da moral e suas bases cerebrais.

A história oficial do TDAH também desconsidera a especificidade da condição descrita por Still: não se tratava de um problema específico da atenção e da hiperatividade. É importante notar que, na lista dos nove sintomas mais importantes acima comentada, vemos que 
a desatenção e a hiperatividade não estão incluídas. O médico inglês citava William James quando estabelecia a conexão entre a desatenção, o defeito moral e a patologia da vontade. Para James, o esforço da atenção era o fenômeno essencial da vontade. Corroborando essa hipótese, Still recordava que algumas crianças analisadas possuíam uma incapacidade de sustentar a atenção; no entanto, a falta de atenção não era um fator de destaque na descrição de Still. $\mathrm{Na}$ sua opinião, ela era importante na medida em que, teoricamente, confirmava que o transtorno era causado pela deficiência da vontade inibitória. As condutas imoral, amoral e perigosa eram o problema maior dos casos analisados. As crianças possuíam algo em comum: elas eram um perigo para si e para a sociedade e deveriam ser tratadas com seriedade e urgência. Still analisava a infância perigosa. Nos seus relatos, brincadeiras e atitudes violentas, envolvendo fogo, facas e garfos e casos de fúria violenta, eram comuns. Um dos meninos, de cinco anos e quatro meses, descrito como extremamente cruel e violento, foi institucionalizado em um orfanato; um dos garotos tentou se matar; outro menino analisado quase foi mandado para o asilo devido aos seus atos perigosos. Os relatos sobre movimentos violentos como bater a cabeça com força contra a mesa e contra a parede eram também constantes. A infância perigosa, portanto, não era uma preocupação apenas de Still.

\section{O contexto das análises de George Still}

Uma análise dos volumes do The Lancet da época nos oferece uma ideia sobre o debate inglês em torno da infância perigosa e do defeito moral. O tema era recorrente (Pope, 1901; Potts, 1904). No volume de 26 de outubro de 1895, a matéria intitulada Crianças criminosas relatava o caso de um bebê de quatro meses morto pela irmã de três anos de idade, aparentemente, por ciúme. O comentário do artigo, feito por um autor anônimo, recorda a análise de Still em dois aspectos: a polaridade entre as causas biológicas e ambientais e a ênfase no perigo que tais crianças representavam: "Baseado na análise dos fatos, é impossível dizer até onde a ausência de autocontrole resulta das condições mentais defeituosas, até onde ela deriva das falhas da educação e do treino ou de outras circunstâncias ambientais" (Infant Criminals, 1895, p. 1056). Como Still, o artigo dizia que pouco se sabia sobre o desenvolvimento moral da criança. O caso exigia o estudo do desenvolvimento das paixões, do autocontrole e da interferência do ambiente e da saúde física no controle moral.

No processo de naturalização da moral, alguns médicos vinculavam o problema prático e social do indivíduo moralmente defeituoso ao quadro patológico do indivíduo mentalmente fraco (feeble-minded) e do imbecil moral. Esses termos descreviam deficiências mentais menos graves que a imbecilidade e eram normalmente associados à criminalidade. Smith (1991) demonstra que, em suas origens, a categoria da imbecilidade moral não foi nem legal nem médica, mas derivou do trabalho de observação e registro dos oficiais médicos das prisões inglesas, interessados no estudo dos criminosos sobre os quais a punição era ineficiente. Em 1904, o termo já era amplamente usado. No Relatório da Comissão Royal sobre o Cuidado e o Controle do Mentalmente Fraco do mesmo ano, tais categorias eram assim definidas: as pessoas de mente fraca eram capazes de manter suas vidas sob circunstâncias favoráveis, mas eram incapazes, devido a um defeito mental existente desde o nascimento ou cedo na vida, de competir em igualdade com seus pares e de gerenciar suas vidas com prudência; os imbecis morais eram pessoas que desde uma tenra idade manifestavam um defeito mental vinculado à propensão ao vício e ao crime. Neles, a punição tinha pouco ou quase nenhum efeito. Embora as categorias 
do imbecil moral e do mentalmente fraco se diferenciassem, nem sempre a separação entre elas era clara. Por vezes, o mentalmente fraco era fraco apenas moralmente, e, nesse sentido, se aproximava da descrição do imbecil moral.

Potts (1904) explicava as origens do problema em uma outra publicação do The Lancet. Nessas patologias, as causas principais da fraqueza mental eram a nutrição deficiente nos primeiros anos de vida e a tendência hereditária às atitudes criminosas, ao alcoolismo e à insanidade. Os indivíduos acometidos possuíam responsabilidade atenuada, sem senso de honra e vergonha, e eram preguiçosos e egoístas. O autor chamava a atenção para os casos femininos. As insanas morais eram garotas de forte inteligência, mas sem senso de honra e modéstia. Elas eram mulheres jovens, patologicamente não suscetíveis de educação moral e religiosa.

Eu não preciso lembrar a vocês que em meninas cujas qualidades morais e intelectuais são defeituosas, as paixões mais baixas são quase sempre fortes e incontroláveis (...) Eu classifico de moralmente insanas as garotas de inteligência forte que não possuem senso de honra e modéstia, não são suscetíveis de ensinamento moral e religioso e, dessa forma, diferem enormemente da maioria das meninas; nada pode impedi-las de mentir ou de roubar. (Potts, 1904, p. 1211)

Se as causas eram biológicas ou não, o tratamento deveria ser a institucionalização em casas de trabalho, o ensino das regras de higiene, a ingestão de comida natural e não estimulante, ar fresco, banhos e exercícios.

Nos discursos da imbecilidade e da imoralidade infantil, iniciados ao menos 24 anos antes da descrição de Still, Rafalovich (2002) situa as origens da problemática que estaria nas bases da história da criança TDAH: a tentativa de biologização e patologização da moral. Para o autor, era esse o pano de fundo que sustentava a opinião de Still. Mas a história da patologização da infância amoral/ imoral é ainda mais antiga. A preocupação com a vida moral e educacional da criança é um assunto médico desde a primeira metade do século XIX. Naquela época, a insanidade moral era definida como desordens do controle moral que não manifestavam um déficit cognitivo. O diagnóstico tornou-se amplamente utilizado no universo infantil. Mais tarde, o termo foi substituído por imbecil moral, e estimulou a admissão de inúmeras crianças e adolescentes amorais e imorais em hospitais psiquiátricos.

A fala de Still vinculava-se a diversos discursos e práticas que marcaram a ciência e a sociedade de seu tempo. Dentre elas, estava o desenvolvimento de uma preocupação científica, médica, econômica e social com a infância, o fortalecimento institucional e profissional da Psicologia e da pedagogia do desenvolvimento fundamentadas nas teorias fisiológicas, a busca pela sede biológica, na maior parte das vezes neurológica, da moral, a defesa moral do controle dos instintos e dos impulsos imediatos pelas instâncias mais nobres da consciência, da razão e da vontade e a afirmação do discurso preventivo contra as patologias da moral. Essas são as vozes presentes nas conferências de Still. A condição mórbida que ele descrevia foi criada pelas demandas dos saberes legais e pela necessidade política e moral de encontrar soluções para o alcoolismo, a prostituição e a delinquência.

\section{Duas variáveis históricas: a educação infantil e a medicalização do comportamento}

A existência de uma função reguladora e inibitória natural era uma necessidade social. A neurofisiologia da vontade inglesa foi um ataque metafísico à metafísica que atendia 
certas necessidades sociais, econômicas e científicas da época. O ponto de vista de Still era, por certo, neurológico, e pode ser incluído na vertente que tentou resolver o problema metafísico, metodológico e social da vontade através do reducionismo fisiológico. Mas, quando falava das causas da patologia da moral, o médico inglês fazia uso de analogias teóricas e de pressupostos metafísicos. A força de seu argumento não se apoiava em nenhuma descoberta científica específica, e a neurologia que ele descrevia não era tão precisa e meticulosa como afirmam os historiadores internos do TDAH que fizeram a releitura dos seus textos.

Além disso, a solução neurológica não era a única disponível. No Inglaterra do final do século XIX, todos os componentes para uma avaliação mais compreensiva sobre as crianças moralmente deficientes estavam presentes, ainda que dispersos: a necessidade de uma discussão mais positiva e preventiva para a delinqüência juvenil tinha sido reconhecida, o estabelecimento da educação compulsória universal aumentou o número de crianças que não conseguiam se enquadrar nas exigências escolares, a crença que os problemas de tais crianças demandavam um trabalho multiprofissional se fortalecia, já existiam clínicas experimentais nas quais médicos e psicólogos trabalhavam juntos e alguns psiquiatras começavam a reconhecer que crianças e adolescentes tinham problemas diferentes dos adultos e necessitavam de serviços separados; o solo estava formado para a irrupção de novas teorias do comportamento.

Mas, na análise de Fuchs (2004), os saberes da Psicologia do desenvolvimento e da pedagogia experimental não impulsionaram nenhuma reforma educacional ampla. Os dados produzidos por essas ciências quase nunca foram convertidos em propostas práticas. O exemplo dado é o alemão. A teoria educacional de Johan Friedrich
Herbart liderava a cena pedagógica da Alemanha, no final do século XIX, e nela moral e corpo eram estâncias separadas. A escola deveria ser um empreendimento puramente moral. Esse exemplo apenas nos prova que, historicamente, na prática educacional, institucional e terapêutica, as técnicas morais de controle da natureza nunca foram realmente banidas. O treino moral da vontade e da atenção era o mais enfatizado.

O ensino da ordem e da regularidade continuava sendo recomendado, além de exercícios físicos e de outros tratamentos sugeridos pelo credo higienista. A fraqueza moral infantil era tratada através da disciplina e do distanciamento da vida agitada e desregrada. Contra ela, era pregado o treino do autocontrole. Esse quadro mudou por volta de 1920, com o fortalecimento da tendência de psicologização do comportamento infantil. O problema moral não era mais resolvido pelo aprendizado do autocontrole, mas através do tratamento psicológico e médico. Nos anos 30 e 40, o deslocamento da leitura moral da doença mental infantil para a leitura médica e psiquiátrica baseou-se principalmente na análise das relações familiares patogênicas. Porter (2001) e Bakker (2001) descrevem um processo de medicalização do comportamento amoral infantil que, em seu início, foi biológico, aos poucos tornou-se psicológico e assim permaneceu até a década de 70. Durante o período psicodinâmico, as explicações biológicas e cerebrais para as patologias da moral, da ação e da atenção não foram abandonadas. Elas estavam lado a lado, competindo e dialogando com as teses psicodinâmicas.

Na primeira metade do século XX, a distinção e a separação entre as teorias psicodinâmicas e biológicas nem sempre era possível. Esse aspecto não é revelado pelo discurso oficial do TDAH. Ele conta a história do predomínio do pensamento biológico e das oposições entre as causas orgânicas e reais da patologia e suas 
imitações sociais e psicológicas. No entanto, esse argumento é desafiado até mesmo quando analisamos as categorias diagnósticas incluídas na histórica que o legitima. Por volta das décadas de 20 e 30, várias explicações biológicas para a síndrome hipercinética surgiram na literatura médica de diferentes países. Para Nefsky (2004), as teorias de Kahn e Cohen sobre a existência de uma organic drivenness foram as mais importantes. Elas também estão incluídas na historiografia do TDAH. Mas, para Kahn e Cohen (Nefsky, 2004), a existência de uma causa biológica para a patologia não eliminava as bases psicológicas do transtorno. A dificuldade em controlar certos impulsos resultava de uma mudança orgânica periférica à constituição do sujeito, contra a qual o esforço individual voluntário era um mecanismo eficiente. Fatores psicológicos e neurológicos estavam envolvidos na patologia da hiperatividade, e ambos eram alvo do tratamento.

$\mathrm{Na}$ história neurobiológica do TDAH, um outro capítulo importante é dedicado à origem do tratamento com estimulante, e, nesse caso, Charles Bradley é o nome mais citado. Diferentemente do que a versão oficial nos conta, mesmo na história farmacológica, a explicação para o transtorno não era de todo biológica. Em sua pesquisa, Bradley afirmava que o medicamento estimulava as partes do córtex responsáveis pelo processo de inibição do comportamento e assim auxiliava no tratamento da hiperatividade. Sua pesquisa comprovava as bases neurofisiológicas do transtorno, mas ele oferecia uma explicação para o problema que era também psicodinâmica. As crianças sem interesse pela escola, incapazes de controlar seus comportamentos impulsivos e suas emoções estavam quase sempre envolvidas em situações de conflito pessoal.

Comentando o trabalho de Bradley, Nefsky (2004) afirma que "seu estudo do efeito do tratamento medicamentoso em crianças hiperativas associa Bradley naturalmente ao pensamento biomédico, mas sua teoria etiológica não postulava um mecanismo neurológico consistente nas bases da hiperatividade. Na verdade, por fim, ele usava conceitos psicodinâmicos, como a noção de conflito pessoal" (p. 19). Essa é também a análise de Singh (2007). Devido à força da interpretação psicanalítica, o campo psiquiátrico era caracterizado pela mistura entre as explicações biológicas e psicológicas. De certa forma, na conceituação da hiperatividade e na psiquiatria infantil, as perspectivas psicodinâmicas dominavam o cenário.

\section{A encefalite letárgica na história do TDAH}

A epidemia da encefalite foi uma infecção misteriosa, até hoje não desvendada, que surgiu nos últimos anos da Primeira Guerra Mundial e desapareceu por volta de 1940, ao ser classificada como uma síndrome amorfa de interesse marginal (Kroker, 2004). Ela foi nomeada pelo neuroanatomista austríaco Constantin von Ecônomo, em 1917, mas outros cientistas em outros países também se ocuparam de sua investigação.

Embora a encefalite seja citada como uma das mais importantes classificações precursoras do TDAH, as possíveis similaridades entre as duas patologias nem sempre são comentadas. Elas são primeiramente semelhantes por incluírem em suas descrições uma pletora de sintomas extremamente diversos. As duas desordens tornaram-se pontos de pauta nas agendas da saúde pública, foram alvo de um enorme investimento financeiro, impulsionaram uma enorme produção científica e acadêmica sobre o corpo e o cérebro, em ambas as tecnologias de visualização, exerceram um poderoso efeito em sua legitimação e, em parte, ambas se apoiaram na pesquisa cerebral dos sistemas inibitórios, fortalecendo a interpretação neurofisiológica da patologia mental. 
No debate científico da primeira metade do século XX, nas ciências da vida, as tecnologias visuais eram vistas como a chave para o progresso científico. No caso da encefalite, as tecnologias de visualização eram vinculadas ao estudo da infectologia e da bacteriologia que pesquisava a causa da doença ou seu agente ainda invisível. Ser invisível para as tecnologias da época era um entrave à revelação da verdade da encefalite. A pesquisa neurológica da encefalite também fez uso das tecnologias cinematográficas. Um exemplo foi o trabalho do neurologista americano Frederick Tilney, de 1918 (Cartwright, 1995). A encefalite reunia sintomas característicos das patologias orgânicas e das psicogênicas. Era preciso distinguir o quadro orgânico de sua imitação psíquica, e, através da utilização das tecnologias cinematográficas, Tilney esperava identificar os movimentos mais sutis, manifestados apenas pelos indivíduos organicamente afetados. Na história recente do TDAH, são as tecnologias de imagem cerebral que prometem a visualização objetiva da causa da patologia que, no entanto, também permanece invisível. O fato de ser considerada uma epidemia de importância pública fazia da encefalite uma patologia ainda mais útil e atraente para os neurologistas. O elo entre neurologia, bacteriologia e saúde pública poderia ser traçado. Hoje em dia, também já ouvimos falar de uma epidemia do TDAH, e o diagnóstico tem sido oficialmente descrito como uma questão de saúde pública, principalmente no contexto americano.

A encefalite passou a chamar a atenção dos neurologistas americanos por volta de 1918 quando, capturando a atenção da bacteriologia, da epidemiologia e da saúde pública americana, ficou conhecida como a patologia do momento (Kroker, 2004). Para a neurologia nova-iorquina, a encefalite trazia uma esperança: a vinculação do saber neurológico ao campo da saúde pública e à pesquisa laboratorial, uma das ciências mais valorizadas na época. Através de seu estudo, a neurologia e a psiquiatria abandonariam a prática diagnóstica incerta e vaga, e sua importância no cenário científico nacional e internacional seria finalmente reconhecida. A autoridade neurológica precisava ser construída, e a encefalite parecia oferecer o modelo de investigação a ser seguido.

As expectativas iniciais em torno da encefalite, no entanto, não se confirmaram. Após anos de disputas políticas, de controvertidas investigações clínicas e epidemiológicas, o quadro mórbido descrito sobre ela havia mudado tanto que alguns médicos diziam que uma outra patologia era investigada sob o mesmo nome. A relação com as pesquisas de base laboratorial tornou-se controversa, e o interesse político e financeiro pela doença desapareceu, já que ela não era mais uma promessa científica e uma possibilidade de afirmação da disciplina neurológica. As esperanças iniciais vinculadas às possibilidades de tratamento também fracassaram. Grande parte das vítimas da encefalite ainda era tratada em instituições para epiléticos, mentalmente fracos e doentes de Parkinson. A vacina usada, além de ineficiente, não era facilmente disponibilizada pelos laboratórios. A encefalite passou a ser descrita como uma síndrome de origem indeterminada, vinculada obscuramente à fisiologia patológica cerebral.

As épocas de indefinições, incertezas e obscuridades, por suas fragilidades e seus mistérios, trazem consigo uma riqueza singular. Elas impõem desafios e urgências que clamam por respostas, e estas são quase sempre diversas e plurais. A encefalite era vista como uma doença misteriosa, estranha, fantasmagórica, que desafiava o conhecimento neurofisiológico clássico. As pessoas atingidas manifestavam crises extraordinárias e instantâneas, nas quais estados catatônicos, tiques, sintomas característicos da doença de Parkinson, 
alucinações, obsessões e mais 30 ou 40 outros sintomas eram vivenciados. Terminada a crise, os sintomas simplesmente desapareciam. A neurofisiologia clássica, baseada no estudo dos centros e funções cerebrais e nas gradações entre eles, não possuía respostas para o problema. A encefalite criou também um outro dilema para a neurologia da época: sem a análise da identidade do paciente, era impossível compreender sintomas tão diversos, já que cada indivíduo manifestava um tipo diferente de encefalite.

Sacks (1990) argumenta brilhantemente que a epidemia da encefalite não possibilitou apenas o fortalecimento político e institucional de uma neurologia biológica reducionista. Ao lidar com a patologia, muitos médicos passaram a acreditar que, na prática clínica, o organismo como um todo - físico e psíquico - deveria ser considerado em sua unidade integradora. O processo terapêutico envolvia a criação de reintegrações singulares e individuais. Além disso, para alguns médicos, nem todo sintoma da encefalite era negativo. Em muitos casos, eles eram libertadores e restauradores; em outros casos, eles eram apenas manifestações comportamentais não necessariamente patológicas.

Por um lado, a leitura de Sacks sobre a encefalite é otimista. Ele descreve como o interesse público e científico pela desordem propiciou um desenvolvimento extraordinário do conhecimento da fisiologia humana, de suas disfunções, de seu potencial regenerador, de sua flexibilidade e de sua integração com a esfera psíquica. O corpo era descrito como um todo físico, químico, biológico, psicológico e sociológico. A encefalite não foi apenas uma patologia neurobiológica e cerebral, um parente longínquo do TDAH. Mas essa dimensão de sua história também não é contada pelos historiadores dessa patologia.

\section{Considerações finais}

O TDAH foi constituído na economia biomédica da atenção, característica das últimas décadas do século XX. Ao mesmo tempo, ele pertence a um período que extrapola a criação de seu conceito diagnóstico e o vincula à história do sujeito cerebral. Sendo parte de um processo mais geral de somatização e cerebrização da identidade, ele pertence à história da constituição das biologias morais da vontade e da atenção.

A defesa da causa cerebral e neurológica da patologia mental também possui uma história. Seus argumentos, seus métodos e suas tecnologias mudaram e se transformaram, fizeram parte de diferentes regimes científicos e discursos morais, mas, em todos eles, as descrições biológicas das patologias da atenção e da vontade permitiram que os valores morais dominantes em cada época fossem naturalizados e inscritos no corpo.

No entanto, não queremos dizer que o diagnóstico do TDAH seja um engodo e que a condição patológica que ele descreve seja inexistente. Tomamos emprestadas as análises de Young (1995) sobre a desordem do stress pós-traumático - PTSD: não é a dúvida sobre a existência da patologia que nos separa do ponto de vista psiquiátrico, mas nossas concepções divergentes sobre as origens de sua realidade. Para Young, a PTSD é um produto cultural criado no encontro de determinadas tecnologias diagnósticas, racionalidades científicas e clínicas e concepções sobre a natureza humana. Em sua temporalidade recente, o TDAH e a condição existencial que ele descreve foram constituídos no espaço fronteiriço habitado pelas tecnologias de saber-poder que possibilitaram a emergência do indivíduo empreendedor, gestor de si e persistente em sua vontade, do eu neuroquímico e cerebral, do indivíduo visto como um risco para si e 
para a sociedade e do eu no qual o desejo de risco é uma ameaça para as sociedades de segurança. Ele não somente nasceu desse solo, mas participou e participa ativamente de sua constituição.

Neste artigo, mostramos como a história oficial do TDAH é um instrumento potente de legitimação do discurso neurobiológico. Ela nos é útil por oferecer dados sobre o processo de cerebrização da moral e da vontade, do qual o diagnóstico do TDAH faz parte. No entanto, ela unifica esse processo, emprestando às teorias que a apoiavam uma face biológica reducionista nem sempre fiel aos postulados defendidos. Além disso, como tecnologia de legitimação do discurso científico purista, omite as faces morais e políticas de seu discurso e suprime as outras vozes que participaram da história da compreensão e do tratamento das patologias da atenção e da hiperatividade, que, na história oficial do TDAH, são inexistentes ou insuficientes.
Como Aranowitz (1998) enfatiza, uma patologia só pode ser compreendida através da análise conjunta de sua biologia, das aspirações disciplinares em torno de sua pesquisa, das organizações burocráticas que a financiam e a sustentam, de sua terapêutica, das mudanças em suas práticas investigativas e da forma como o indivíduo e a sociedade a experienciam. No caso da encefalite letárgica, para surpresa de muitos críticos, a consideração desses fatores não revelou apenas o fortalecimento da interpretação neurobiológica reducionista. Seguindo o exemplo de Oliver Sacks, seria preciso analisar a face otimista e positiva da história das patologias da atenção e da hiperatividade. Essa seria a história das margens do TDAH, e talvez, a história das margens da atenção. Ao se diferenciar da análise biológica reducionista, possivelmente ela oferecesse grades interpretativas e intervencionistas mais éticas e plurais para a compreensão das patologias da atenção e da ação.

\section{Luciana Vieira Caliman}

Pós-doutora em Psicologia pelo Programa de Pós-Graduação em Psicologia do Instituto de Psicologia da Universidade Federal do Rio de Janeiro, Rio de Janeiro, RJ - Brasil. Professora Adjunta do Programa de PósGraduação em Psicologia Institucional, Universidade Federal do Espírito Santo, Vitória, ES - Brasil.

Endereço para envio de correspondência:

Rua Petrolino César de Moraes, 210, Casa 25, Mata da Praia - Vitória, ES - Brasil - CEP: 29066-320.

E-mail: calimanluciana@gmail.com 


\section{Referências}

Aranowitz, R. A. (1998). Making sense of illness: Science, society and disease. Cambridge: Cambridge University Press.

Bakker, N. A. (2001). Harmless disease: Children and neurasthenia in the Netherlands. In R. Poter \& M. GijswiitHofstra (Eds.), Cultures of neurasthenia from beard to the First World War (pp. 309-327). Amsterdam: Rodopi.

Barbetti, H. V. (2003). A historical phenomenology of attention deficit/hyperactivity disorder. Tese de Doutorado, Faculty of the McAnulty College and Graduate School of Liberal Arts, Duquesne University, Duquesne.

Barkley, R. A. (1997). ADHD and the nature of self-control. London: The Guilford Press.

Caliman, L. (2006). A biologia moral da atenção: a constituição do sujeito (des)-atento. Tese de Doutorado, Instituto de Medicina Social, Universidade do Estado do Rio de Janeiro, Rio de Janeiro.

Cartwright, L. (1995). Screening the body - tracing medicine's visual cultural. Minneapolis: University of Minnesota Press.

Conrad, P. (1975). The discovery of hyperkinesis: Notes on the medicalization of deviant behaviour. Social Problems, 23(3), 12-21.

Conrad, P. (1976). Identifying hyperactive children: The medicalization of deviant behaviour. Lexington, Mass: Lexington Books.

Degrandpre, R. (2000). Ritalin nation - Rapid-fire-culture and the_transformation of human counciousness. New York: W. W. Norton \& Company.

Diller, L. (1998). Running on Ritalin - A physician reflects on children, society, and performance in a pill. Canadá: Bantam Books.

Dumit, J. (2000). When explanations rest good-enough: Brain sciences and the new socio-medical disorders. In M. Lock (Ed.), Living and working with the new medical technologies: intersections of inquiry. Cambridge, UK: Cambridge University Press.

Dupanloup, A. (2004). L'Hyperactivité infantile: Analyse sociologique d'une controverse socio-medicale. Tese de Doutorado, Université de Neuchâtel, Faculté des Sciences Economiques et Sociales, Neuchâtel.

Fuchs, E. (2004). Nature and Bildung: Pedagogical Naturalism in Nineteenth-Century Germany. In L. Daston (Ed.), The Moral Authority of Nature. Chicago, US: The University of Chicago Press.

Infant Criminals. (1895). The Lancet, 146(3769), 1324-1895. (Correspondência anônima)
Kroker, K. (2004). Epidemic Encephalitis and American Neurology, 1919-1940. Bulletin of the History of Medicine, 78(1) 108-148.

Nefsky, C. (2004). A conceptual history of attention deficit and hyperactivity disorder. Dissertação de Mestrado, Memorial Studentship for the History of Medicine, Faculty of Medicine and Health Sciences, University of Ottawa, Ottawa.

Pope, F. (1901). The physical causes of the slighter forms of mental defects in children. The Lancet, 158(4062), 11-18.

Porter, R., \& Gijswijt-Hofstra, M. (2001). Cultures of neurastenia from beard to the First World War. Amsterdam - New York: Rodopi.

Potts, W. A. (1904). The problem of the morally defective. The Lancet, 164(4235), 1210-1211.

Rafalovich, A. (2002). Framing the ADHD child: History, discourse and everyday experience. Tese de Doutorado, Department of Anthopology \& Sociology, University of British Columbia, Vancouver.

Sacks, O. (1990). Postencephalitic syndromes. In G. Stern (Ed.), Parkinson's disease (pp. 415-429). Baltimore: The John Hopkins University Press.

Schrag, P., \& Divoky, (1975). D. The myth of the hyperactive child and other means of child control. New York: Pantheon.

Singh, I. (2007). Not just naughty: 50 years of stimulant drug advertising. In A. Tone \& E. Watkins (Eds.), Medicating modern American - Prescription drugs in history (pp. 131-155). New York: New York University Press.

Smith, R. (1991). Legal frameworks for psychiatry. In J. Berrios \& D. Freeman (Eds.), 150 years of British psychiatry, 1841-1991 (pp. 137-151). London: Gaskell.

Still, G. (1902, 12 de abril). Some abnormal psychical conditions in children - Lecture I. The Lancet, 1008-1012.

Still, G. (1902, 19 de abril). Some abnormal psychical conditions in children - Lecture II. The Lancet, 1079-1082.

Still, G. (1902, 26 de abril). Some abnormal psychical conditions in children - Lecture III. The Lancet, 1163-1167.

Werner, J. (2001). Saúde \& educação - desenvolvimento e aprendizagem do aluno. Rio de Janeiro: GryphusIn.

Young, A. (1995). The harmony of illusions: Inventing posttraumatic stress disorder. Princeton: Princeton University Press. 